\title{
EDITORIAL AND COMMENT \\ Taking an Interdisciplinary Approach to Understanding and Improving Medication Adherence
}

\author{
Kenneth G. Saag, MD, MSc' ${ }^{7}$ Smita Bhatia, MD, MPH' ${ }^{2}$, Michael J. Mugavero, MD, MHSc ${ }^{3}$, and \\ Jasvinder A. Singh, $M D, M P H^{1,4}$ \\ 'Division of Clinical Immunology and Rheumatology, Department of Medicine, University of Alabama at Birmingham, Birmingham, AL, USA; \\ ${ }^{2}$ Division of Pediatric Hematology-Oncology, Department of Pediatrics, University of Alabama at Birmingham, Birmingham, AL, USA; ${ }^{3}$ Division of \\ Infectious Diseases, Department of Medicine, University of Alabama at Birmingham, Birmingham, AL, USA; ${ }^{4}$ Medicine Service, Veterans Affairs \\ Medical Center, Birmingham, AL, USA.
}

J Gen Intern Med 33(2):136-8

DOI: $10.1007 / \mathrm{s} 11606-017-4215-7$

(c) Society of General Internal Medicine 2017

$\mathrm{T}$ he World Health Organization defines adherence as "the extent to which a person's behavior-taking medication, following a diet, and/or executing lifestyle changes-corresponds with agreed recommendations from a health care provider." While adherence research has focused primarily upon multiple dimensions related to taking medications in a manner congruent with prescriber recommendations, other aspects of the broader definition of adherence, including utilization of medical care and engagement in self-care behaviors, have received increasing attention in recent years. Moreover, with greater emphasis on patient-centered care and shared decision making between consumers of care and their health care provider(s), the pejorative term compliance has fallen out of favor and has been replaced nearly universally with the term adherence. Also, although adherence has traditionally focused upon medications used to manage long-term, chronic conditions (e.g., hypertension, diabetes, heart disease, rheumatic conditions), analogous principles are germane and have been applied to curable medical conditions (e.g., cancer, tuberculosis, hepatitis $\mathrm{C}$ virus infection).

Adherence, in the broadest context, is a well-recognized requirement for positive health outcomes for many medical conditions. ${ }^{1}$ Longevity, quality of life, sustained presence in the workforce, and overall health are improved with adequate levels of adherence to, and persistence with, medication regimens and self-care behaviors for the management of medical conditions, including diabetes, asthma, hypertension, cancer, and HIV. ${ }^{2}$ Despite the well-established benefits of persistent medication adherence, many people on long-term treatment for chronic conditions struggle to achieve or maintain high rates of adherence, with some rates as low as $6 \% .^{3}$ Almost $50 \%$ of patients with chronic disease are not following the recommended medication treatment at 1 year after diagnosis. ${ }^{4}$

Published online December 4, 2017
This rate has shown very little change over the past three decades. Estimates of costs related to medication nonadherence are in the billions of dollars per year in the US alone. $^{4,5}$

Not surprisingly, efforts to better understand the facilitators of, and barriers to, medication adherence have proliferated. As it relates to medication adherence, efforts to reduce toxicity, dosing burden, and demands of regimens have dramatically improved recommended courses of treatment. There remains, however, a significant need to optimize adherence for patients in the US. ${ }^{6}$ A recent conference brought together providers, researchers, and industry representatives to examine patientcentered barriers to, and solutions for, improving medication adherence, including strategies for communicating with patients.

Current evidence regarding the efficacy of individual or combined interventions to improve adherence is mixed, ${ }^{7}$ and new approaches for enhancing medication adherence are needed. We believe that it is time that adherence researchers start "thinking outside the pill bottle." Indeed, beyond medication adherence for chronic conditions, the adherence field has seen a renaissance in many disease areas, with extension of these principles to include congruence of patient behavior with recommended lifestyle modifications and self-care behaviors beyond medication taking. Understanding the multiple and multilevel factors that drive adherence behaviors, in the broader context, is essential to developing effective, patientcentered interventions to improve adherence and patient outcomes for both curable and chronic conditions.

In February 2016, The University of Alabama at Birmingham (UAB) hosted "Interdisciplinary Approaches to Understanding and Improving Adherence," a cross-disciplinary meeting of numerous experts in adherence and adherence research, representing various medical specialties, scientific disciplines, and stakeholders from 12 institutions across the US. The goal of the meeting was to review the state-of-the-art in therapeutic and health care adherence research and identify research priorities based on key unanswered questions in the field. The attendees discussed current concepts in adherence research and clinical practice, and worked together to develop a research agenda that would move the field forward. Breakout sessions focused on adherence through the lens of health 
communications, health disparities, behavioral models and interventions, and pharmacoepidemiology and measurement. The articles that follow in this symposium were developed based on the discussions and plenary sessions at this meeting.

In "Advancing the Science and Practice of Medication Adherence," Stirratt and colleagues provide a review of adherence as a multidimensional construct with three components: initiation, implementation, and persistence. ${ }^{8}$ These multiple adherence dimensions are dynamic, and in many cases function independently of one another. Adherence can be measured using various indirect and direct methods, each with their own advantages and disadvantages. The paper also describes several successful patient-, provider-, and systemslevel approaches to improving medication adherence. Finally, the paper lists key topics for future adherence research identified by the roundtable attendees.

McQuaid and Landier discuss the intersection of culture and medication adherence and the impact of poor medication adherence on health outcomes disparities in their paper " $\mathrm{Cul}$ tural Issues in Medication Adherence: Disparities and Directions." Factors such as exposure to adversity and perceived discrimination can affect adherence to medications, as can cultural beliefs about the necessity of medication and participation in the health care system. The authors also discuss the impact of complementary and alternative medications and language barriers on adherence. The paper describes the role of the healthcare provider in acknowledging and discussing cultural issues with their patients and then implementing interventions to improve adherence in a culturally sensitive manner, and concludes with a list of key topics for ongoing adherence research utilizing culturally appropriate and effective communication and training at the patient, provider, and systems level.

In "Advantages to Using Social-Behavioral Models of Medication Adherence in Research and Practice," Amico and colleagues review the contributions of social-behavioral science to developing comprehensive models and frameworks of adherence and the application of explanatory models to practice, research development, and scientific progress. ${ }^{10}$ The authors argue that the act of taking a medication is only one part of achieving adherence, and a number of other factors affect medication taking that need to be considered in the realworld setting, such as the patient's acceptance of the condition, perception about the necessity of treatment, attitude toward the medication, and the ability to take the medication in a realworld setting. Social-behavioral models provide a framework that takes into account how these multilevel factors are necessary for rational development and testing of effective interventions to improve adherence. In this article, Amico and colleagues provide a review of social-behavioral models using examples from HIV medication adherence research, with the goal of demonstrating how these models can be used efficaciously in both clinical practice and research. They conclude with practical guidance on how to select, tailor, operationalize, and use a social-behavioral model of adherence.
Together, this collection of state-of-the-art papers provides an in-depth and multifaceted look at the current state of knowledge in medication adherence, the cultural considerations that shape patient and provider approaches to medication adherence, the social-behavioral models that can be applied to develop new interventions to improve medication adherence, and future directions in adherence research.

Acknowledgements: The conference leaders, Kenneth G. Saag, MD, MSc, Smita Bhatia, MD, MPH, and Michael J. Mugavero, MD, MHSc, would like to thank Elizabeth Rahn, PhD, Ryan Outman, MS, Eve Markovitz, and the entire team at the UAB for their assistance in organizing the meeting and coordinating development and submission of the conference symposium articles. We would like to thank our conference speakers-K. Rivet Amico, PhD; Jeffrey R. Curtis, MD, MS, MPH; Elizabeth L. McQuaid, PhD, ABPP; Penny Mohr, MA; and Michael J. Stirratt, $P h D$ - as well as our conference breakout session leaders-Jeroan Allison, MD, MS; Hayden B. Bosworth, PhD; Richard Hansen, RPh, PhD, FAPhA; Marie Krousel-Wood, MD; MSPH, Bruce Lambert, PhD; Michael Miller, RPh, DrPH, FAPhA; Paul Muntner, PhD; and Monika Safford, MD. Stacey C. Tobin, PhD, provided editorial assistance in preparing this symposium. Funding for the meeting and for preparing this symposium was provided by the UAB School of Medicine Academic Medical Center of the 21st Century (AMC21) initiative. We would also like to thank the meeting participants from the following institutions for their invaluable input and insights:

Auburn University

Brown University

Cornell University

Duke University

National Institutes of Health (NIH)

Patient-Centered Outcomes Research Institute (PCORI)

Tulane University

University of Alabama at Birmingham

University of Massachusetts-Worcester

University of Michigan

University of Mississippi Medical Center

University of Oklahoma

Corresponding Author: Kenneth G. Saag, MD, MSc; Division of Clinical Immunology and Rheumatology, Department of Medicine University of Alabama at Birmingham, Birmingham, AL, USA (e-mail: ksaag@uabmc.edu).

\section{Compliance with Ethical Standards:}

Conflict of Interest: All authors declare no conflicts of interest.

\section{REFERENCES}

1. Krueger KP, Berger BA, Felkey B. Medication adherence and persistence: a comprehensive review. Adv Ther. 2005;22(4):313-56.

2. Brown MT, Bussell JK. Medication adherence: WHO cares? Mayo Clin Proc. 2011;86(4):304-14. https://doi.org/10.4065/mcp.2010.0575.

3. Haynes RB, Ackloo E, Sahota N, McDonald HP, Yao X. Interventions for enhancing medication adherence. Cochrane Database Syst Rev. 2008;16(2):Cd000011. https://doi.org/10.1002/14651858.CD000011. pub3.

4. Osterberg L, Blaschke T. Adherence to medication. N Engl J Med. 2005;353(5):487-97. https://doi.org/10.1056/NEJMra050100.

5. Sokol MC, McGuigan KA, Verbrugge RR, Epstein RS. Impact of medication adherence on hospitalization risk and healthcare cost. Med Care. 2005;43(6):521-30.

6. Zullig LL, Granger BB, Bosworth HB. A renewed Medication Adherence Alliance call to action: harnessing momentum to address medication nonadherence in the United States. Patient Prefer Adherence. 2016;10:1189-95. https://doi.org/10.2147/ppa.s100844.

7. Kuntz JL, Safford MM, Singh JA, Phansalkar S, Slight SP, Her QL, et al. Patient-centered interventions to improve medication management 
and adherence: a qualitative review of research findings. Patient Educ Couns. 2014;97(3):310-26. https://doi.org/10.1016/j.pec.2014.08.021.

8. Stirratt, MJ, Curtis JR, Danila MI, Hansen R, Miller MJ, Gakumo CA. Advancing the science and practice of medication adherence. $J$ Gen Intern Med. [4198].
9. McQuaid EL, Landier W. Cultural issues in medication adherence: disparities and directions. J Gen Intern Med. [4199].

10. Amico KR, Krousel-Wood M, Bosworth HB, Merlin JS. Advantages to using social-behavioral models of medication adherence in research and practice. J Gen Intern Med. [4197]. 